See Article page 167.

\section{Commentary: How best to quantify an uplifting pectus operation?}

\author{
Aliss Chang, MBChB, and \\ Michael Hsin, MD, FRCS CTh
}

Pectus excavatum (PE) is the most common congenital chest wall deformity, ${ }^{1}$ and Ravitch reported his technique of surgical correction for PE in 1947. In recent years, minimally invasive approaches, in particular the Nuss procedure, have gained popularity. ${ }^{2}$ The passage of the Nuss bar is associated with a risk of injury to retrosternal structures, and although very rare, the outcomes are devastating when they do occur. ${ }^{3}$ To reduce the risks of potentially fatal complications, it is imperative to maximize the substernal space for better visualization while performing dissection and to lessen the risk of intercostal stripping during the implantation of the Nuss bar. ${ }^{4}$

Crane elevation is one such technique that increases the substernal space, and reports have been published with an agreeable safety profile and clinical effectiveness. Hitherto, there has been a lack of quantitative data evaluating the use of this technique. In this issue of the Journal, de Loos and colleagues $^{5}$ report the first quantitative analysis and objective evaluation of the crane technique in sternal elevation and pectus reduction. This study comprises a welldesigned methodology with a clear illustration of the crane technique and the 3-dimensional (3D) imaging system used for data acquisition. Their methodology appears readily replicable for quantitative evaluation of different sternal elevation techniques, which opens the possibility of comparison between different techniques.

The authors used the point of deepest excavation of the anterior chest wall as the point of reference to determine the maximum distance altered by the "lift" of the chest wall as a result of the combined elevation from the crane,

From the Department of Cardiothoracic Surgery, Queen Mary Hospital, Hong Kong. Disclosures: The authors reported no conflicts of interest.

The Journal policy requires editors and reviewers to disclose conflicts of interest and to decline handling or reviewing manuscripts for which they may have a conflict of interest. The editors and reviewers of this article have no conflicts of interest.

Received for publication July 26, 2021; revisions received July 26, 2021; accepted for publication July 30, 2021; available ahead of print Aug 5, 2021.

Address for reprints: Michael Hsin, MD, FRCS CTh, Department of Cardiothoracic Surgery, Queen Mary Hospital, Room 308, New Clinical Building, Hong Kong (E-mail: mkhsin@hotmail.com).

JTCVS Techniques 2021;9:176-7

2666-2507

Copyright (C) 2021 The Author(s). Published by Elsevier Inc. on behalf of The American Association for Thoracic Surgery. This is an open access article under the CC BY-NC-ND license (http://creativecommons.org/licenses/by-nc-nd/4.0/). https://doi.org/10.1016/j.xjtc.2021.07.026

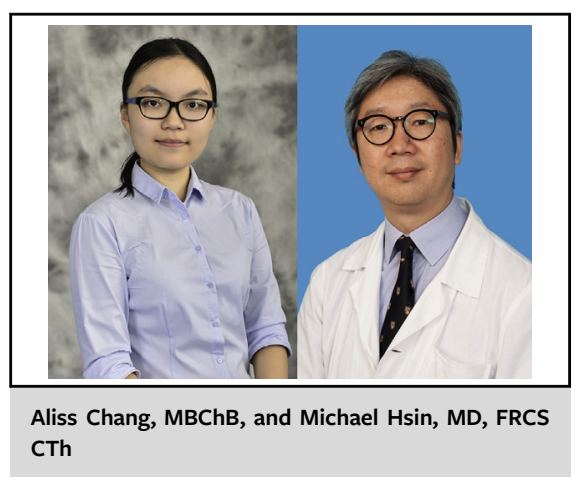

CENTRAL MESSAGE

3D imaging allows quantitative analysis of the crane technique in

the Nuss operation. Future

studies may investigate volumetric changes in the chest wall and measurement of the lifting force required.

ie, lifting of the entire chest wall combined with the reduction of the PE. This is determined by comparing 3D images taken before incision and after crane application. However, PE represents a spectrum of anatomical deformities ranging from the symmetrical to the highly asymmetrical. A linear measurement taken at the deepest depth of the deformity may not provide the full picture of the changes following the application of the crane. Alternative measurement techniques have been described in PE. For example, Uemura and colleagues ${ }^{6}$ used superimposed 3D images from pre- and postoperative images to measure the external sternal angle and elevating distance in both the axial and sagittal planes. Measurements such as 3D volumetric or area calculation may provide more accurate assessments of the changes in the shape and depth of the deformity, which in turn may correlate better than a linear measurement with the actual postprocedural cosmetic effect.

The authors did not investigate the lifting force required to adequately elevate the sternum. It is known that in patients with PE from different age groups, the amount of force required to elevate the chest wall can vary significantly. ${ }^{7}$ It would be helpful to document this information to improve calibration of the amount of lift required and to determine how best to improve this technique in the future.

Overall, this paper is an important step toward quantitative analysis of sternal elevation and pectus correction using 
the crane technique, which will help both clinicians and researchers in the management of this condition.

\section{References}

1. Shamberger RC, Welch KJ. Surgical repair of pectus excavatum. J Pediatr Surg. 1988;23:615-22.

2. Nuss D. Minimally invasive surgical repair of pectus excavatum. Semin Pediatr Surg. 2008; 17:209-17.

3. Bouchard S, Hong AR, Gilchrist BF, Kuenzler KA. Catastrophic cardiac injuries encountered during the minimally invasive repair of pectus excavatum. Semin Pediatr Surg. 2009;18:66-72.
4. Obermeyer RJ, Goretsky MJ, Kelly RE, Frantz FW, Kuhn MA, McGuire MM et al. Selective use of sternal elevation before substernal dissection in more than 2000 Nuss repairs at a single institution. J Pediatr Surg. 2021;56:649-54.

5. de Loos ER, Daemen JHT, Coorens NA, Maessen JG, Vissers YLJ, Hulsewé KWE. Sternal elevation by the crane technique during pectus excavatum repair: a quantitative analysis. J Thorac Cardiovasc Surg Tech. 2021;9: 167-75.

6. Uemura S, Yoshida A, Kuyama H. Analysis of chest wall elevation after the Nuss procedure using $3 \mathrm{D}$ body scanning technique in patients with pectus excavatum. Pediatr Surg Int. 2021;37:777-82.

7. Fonkalsrud EW, Reemtsen B. Force required to elevate the sternum of pectus excavatum patients. J Am Coll Surg. 2002;195:575-7. 